\title{
Stand-off Raman spectroscopic detection of minerals on planetary surfaces
}

\author{
Shiv K. Sharma*, Paul G. Lucey, Manash Ghosh, Hugh W. Hubble, \\ Keith A. Horton
}

Hawaii Institute of Geophysics and Planetology, University of Hawaii, 2525 Correa Rd., HIG, Honolulu, HI 96822, USA

Received 20 June 2002; accepted 15 August 2002

\begin{abstract}
We have designed and developed two breadboard versions of stand-off Raman spectroscopic systems for landers based on a 5-in. Maksutov-Cassegrain telescope and a small (4-in. diameter) Newtonian telescope receiver. These systems are capable of measuring the Raman spectra of minerals located at a distance of 4.5-66 m from the telescope. Both continuous wave $(\mathrm{CW})$ Ar-ion and frequency doubled Nd:YAG $(532 \mathrm{~nm})$ pulsed $(20 \mathrm{~Hz})$ lasers are used as excitation sources for measuring remote Raman spectra of rocks and minerals. We have also made complementary measurements on the same rock samples with a micro-Raman system in 180 and $135^{\circ}$ geometry for evaluating the system performance and for estimating effect of grain size and laser-induced heating on the spectra of minerals using $\alpha$ quartz as a model mineral. A field portable remote pulsed Raman spectroscopic system based on the 5-in. telescope and an $f / 2.2$ spectrograph has been developed and tested. We have also demonstrated a prototype of a combined Raman and laser-induced breakdown spectroscopy (LIBS) system, capable of providing major element composition and mineralogical information on both biogenic and inorganic minerals at a distance of $10 \mathrm{~m}$ from the receiver.
\end{abstract}

(C) 2003 Elsevier B.V. All rights reserved.

Keywords: Raman; LIBS instrument; Mineral detection; Planetary surface; Mars

\section{Introduction}

Advancements in lasers, spectrographs and holographic optical components have made laser

\footnotetext{
* Corresponding author. Tel.: +1-808-956-8476; fax: +1808-956-3188.

E-mail address: sksharma@mano.soest.hawaii.edu (S.K. Sharma).
}

based techniques such as Raman spectroscopy and laser-induced breakdown spectroscopy (LIBS) effective tools for analyzing natural and synthetic materials. Advanced Raman spectroscopic techniques have been employed to investigate the mineralogy of meteorites [1-3], and have been proposed for in situ mineral characterization on planetary surfaces $[4,5]$. Both micro-Raman and remote Raman systems are being considered for 
future exploration on planetary surfaces [6-10]. The feasibility of using stand-off LIBS technique, which is based on detection of atomic emission lines of cations and other species in the laser generated plasma, has been demonstrated for the rapid online determination of the major and minor constituents of mineral drill core samples as well as for space applications [11,12].

Raman spectroscopy, which is based on inelastic scattering of light and provides information about molecular vibrations, offers molecular specificity, structural discernment and relatively simple spectral fingerprints. Advanced Raman techniques are finding increasing applications in a large variety of problems in earth and planetary sciences (e.g. [13$15])$, including high pressure mineralogy $[13,15-$ 18], shock metamorphism (e.g. [19]), graphatization of carboneous matter in metamorphic rocks [20], fluid inclusions in minerals (e.g. [21,22]), pigments in ancient paintings [23], manuscript and other artifacts [24,25], biogenic minerals $[26,27]$ and biomolecules (e.g. [28]). Of interest to the geologic community, and particularly for planetary exploration, is the possibility to unambiguously identify various minerals on planetary surfaces by their characteristic Raman peaks $[6,29,30]$. Most of the current applications in earth and planetary science are based on the microRaman and FT-Raman spectroscopic techniques. Raman spectroscopy can also be conducted with a telescope from a stand-off distance. Performance of remote Raman analysis has been explored theoretically by T. Hirschfeld [31], while the potential of measuring Raman spectra of organic materials [32], minerals, and inorganic materials with a small telescope and $\mathrm{CW}$ laser have been realized $[8,9]$. Raman lidars based on high power lasers and large telescopes have been used for investigating gaseous species in the atmosphere (e.g. $[33,34])$. Raman analyses of solid, liquids and gases have been performed at ranges of $500 \mathrm{~m}$ using a medium power UV laser with large collecting optics [35]. Recently, the feasibility of analyzing rocks and minerals with remote Raman spectroscopy at sample distances of 10 s of meters from the receiver telescope has been demonstrated using modest diameter telescopes, modern efficient spectrometers, and low power lasers similar to those which have already flown on planetary missions [10,36,37].

Landers and rovers are an increasingly important element of NASA's solar system exploration program. Lander and rover sample analysis instrumentation includes methods requiring either close physical contact with a sample such as X-ray fluorescence (XRF) spectroscopy, or even sample acquisition, such as thermal analysis or mass spectrometry. There are inherent limitations to these techniques and limits to their performance at their present state of development. Visible, nearinfrared, and thermal infrared spectroscopy of minerals and compounds all suffer from broad overlapping spectral features which complicate interpretation of their spectra. Sample selection is accomplished using imaging supported by multispectral or remote spectroscopic analysis. The recent experience with Sojourner/Pathfinder emphasized the importance of sample selection, as contact analyses are intensive in time or other resources. The ability to determine which samples within the region may be of specific interest without driving the rover to the various samples can reduce power consumption and risk significantly.

It is the broad, overlapping nature of mineral or chemical spectral features that constitute most of the challenge to interpretation of reflectance or emission spectra. In contrast, Raman spectra of minerals and mineral mixtures exhibit narrow and largely non-overlapping features, which are much more easily identified and separated. This capability enables rapid and model-independent mineralogical analysis of rocks and soils in the vicinity of a lander or a large rover. This stand-off Raman capability does not replace passive remote spectral analysis, which can survey much larger areas in less time, but does offer an entirely new ability to make less ambiguous mineralogical identification.

This paper critically reviews the stand-off Raman systems developed at the University of Hawaii in terms of balancing versatility against the physical limitations required for planetary exploration. We have measured Raman spectra of dozens of rocks and minerals, water and ice, as 
well as of gaseous species in the atmosphere from distances ranging up to $66 \mathrm{~m}[8,10]$

\section{Instrumentation}

In the following sections, we briefly describe prototypes of laboratory and field stand-off Raman spectroscopic systems as well as a combined stand-off Raman and LIBS system developed in our laboratory for detecting minerals and ices on planetary surfaces.

\subsection{A stand-off pulsed Raman spectroscopic laboratory prototype}

The experimental setup for our stand-off pulsed Raman system for measuring spectra of minerals and rocks in the laboratory as well as outdoors is schematically shown in Fig. 1. This SOPRS prototype system consists of a telescope (Meade ETX-125 Maksutov-Cassegrain, $125 \mathrm{~mm}$ clear aperture, $1900 \mathrm{~mm}$ focal length, f/15), a frequency doubled mini Nd:YAG laser source (Model ULTRA CFR, Big Sky Laser, $532 \mathrm{~nm}, 20 \mathrm{~Hz}$ ), and a $0.25 \mathrm{~m}$ spectrograph (Spex Model 270M with 1800 grooves per $\mathrm{mm}$ grating, blazed at $500 \mathrm{~nm}$ )

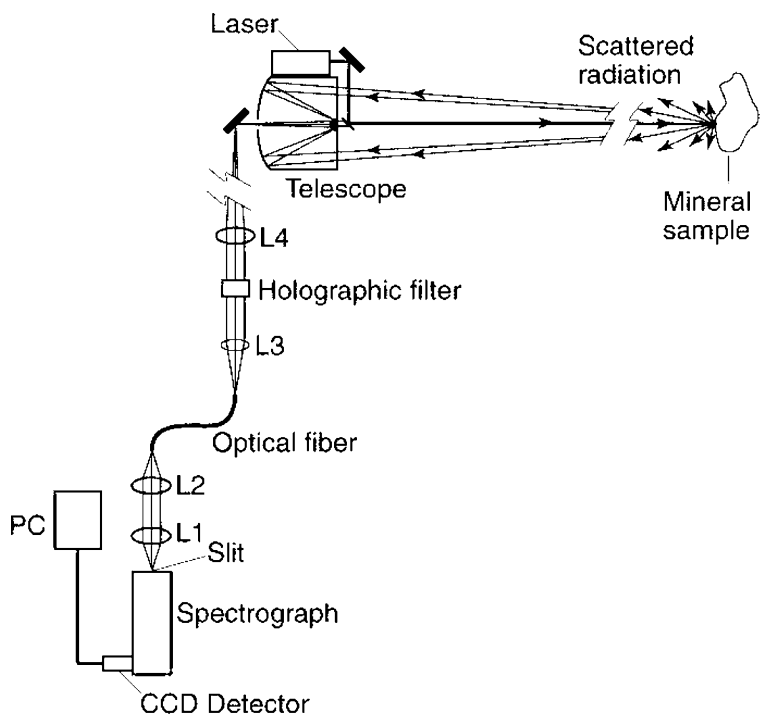

Fig. 1. Schematic diagram of a stand-off pulsed-Raman spectroscopic system developed at the University of Hawaii. equipped with a gated intensified detector (Princeton Instruments Inc. Model I-MAX-1024-E). The maximum power of the laser at $532 \mathrm{~nm}$ is $35 \mathrm{~mJ}$ per pulse, the width of the laser pulse is approximately 8-nanosecond (ns), and the beam divergence is less than 8-milliradian (mrad). The spectrometer has entrance aperture ratio of $f / 4$ and produces an image magnification of 1.23 at the exit. Grating position and slits of the spectrometer can be adjusted remotely with a hand held electronic controller.

In the ETX-125 telescope receiver, light enters through a multi-coated meniscus lens, proceeds to an $f / 2.2$ primary mirror, and then to a convex secondary mirror (diameter $39.4 \mathrm{~mm}, 9.6 \%$ obstruction) that multiplies effective focal length by a factor of 6.8. The use of an oversized $138 \mathrm{~mm}$ diameter primary mirror results in a fully illuminated (unvignetted) field of view significantly wider than can be obtained with Maksutov optics incorporating primary mirrors of the same apertures as their correcting lenses. Raman measurements at distances ranging from 10 to $66 \mathrm{~m}$ were accomplished by focusing the telescope on the sample. The size of the Spex $270 \mathrm{M}$ spectrometer is $43(L) \times 35(W) \times 20 \mathrm{~cm}(H)$, where $L, W$, and $H$, respectively, refer to length, width, and height of this instrument.

The laser is mounted on the side of the telescope and two $45^{\circ}$ small fused quartz glass prisms are used to bring the beam to the center of the telescope to make it a co-axial system (Fig. 1). The main advantage of this arrangement is to get the maximum performance by gathering scattered light from the target in the $180^{\circ}$ (backscattering) geometry while providing the ability to scan the telescope with a two-axis scanning motor.

The telescope is coupled to the spectrograph with a multi-mode fused-quartz optical fiber (200 $\mu \mathrm{m}$ in diameter). A lens (L4) collimates the light from the output of the telescope (see Fig. 1). A holographic super-notch filter was inserted between the collimating lens L4 and a $10 \times$ microscope objective (L3). The L3 lens focuses the scattered light onto the optical fiber. The filter was adjusted to attenuate the elastically scattered and diffuse reflected laser light. The light leaving the optical fiber is collected and collimated by the 
L2 lens (Fig. 1). The objective lens L1 focuses the light at the entrance slit of the Spex 270M imaging spectrograph. The spectrograph has a unique Czerny-Turner configuration for optical correction that provides for exceptional imaging capabilities. The system delivers near perfect spectral imaging over an area 25 wide $\times 12 \mathrm{~mm}$ high in the spectrograph image plane. Raman spectra were recorded with a thermoelectrically cooled gated and intensified CCD detector. The CCD array is $1024 \times 256$ pixels and each pixel is $26 \times 26 \mu^{2}$. The detector is mounted in such a way that the Raman spectrum is dispersed along the horizontal (longer) axis. The signal in the 256 vertical pixels is binned to produce a single channel signal. Under certain cases, the horizontal pixels were also binned in a group of 2- or 3-pixels as one channel to improve signal to noise ratio (SNR). A plot of binned signal versus channel numbers formed the Raman spectrum. The spectra were calibrated to Raman shifts in $\mathrm{cm}^{-1}$. Typical slit widths for Raman spectral measurements were $200 \mu \mathrm{m}$ corresponding to resolution of $\sim 12 \mathrm{~cm}^{-1}$. With slit widths of $400 \mu \mathrm{m}$, the Raman spectra of hydrous minerals with good $\mathrm{S} / \mathrm{N}$ ratio in the $\mathrm{O}-\mathrm{H}$ stretching region were obtained [10]. It should be mentioned here that horizontal binning of the CCD pixels in a group of 2- or 3-pixels does not affect the position (frequency) of the Raman bands but it does increase the $\mathrm{S} / \mathrm{N}$ and lower the spectral resolution.

Two commercial computer programs were used for data collection and reduction with the pulsed remote Raman system. Princeton Instruments WINSPEC 32-bit Windows ${ }^{\circledR}$ software package from Roper Scientific was used for spectral data acquisition from the intensified and gated CCD detector. With this software, data can be acquired both in imaging and spectral mode. Further processing of the spectral data was carried out using GRAMS $/ 32^{\circledR}$ software package from Galactic Industries.

\subsection{A field-portable stand-off pulsed Raman spectroscopic system}

The field-portable remote pulsed Raman spectroscopy system (Fig. 2) is based on the same

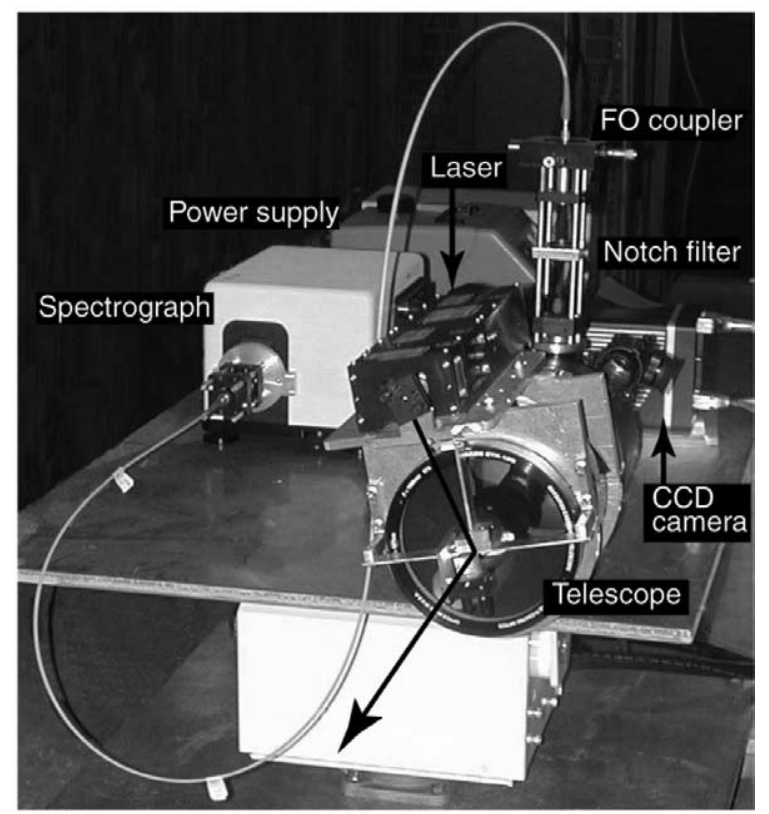

Fig. 2. Photograph of the University of Hawaii's field-portable stand-off pulsed Raman spectroscopic system.

design as the pulsed Raman laboratory prototype described in Section 2.1 above except that we have incorporated a smaller and more efficient $(f / 2.2)$ spectrograph (HoloSpec $f / 2.2$, Kaiser Optical Systems, Inc.). The multi-element lenses used in the $f / 2.2$ holographic axial transmitting imaging spectrograph collect light over a solid angle many times larger than that of Czerny-Turner spectrographs, which operate usually in the range $f / 3.3-f /$ 11. The larger solid angle, coupled with the high $(80 \%)$ diffraction efficiency of the volume holographic transmission grating, results in a greatly improved light throughput (at least by a factor of 4 as compared with the throughput of a $f / 4$ spectrograph for the same size of the entrance slit). The size of the HoloSpec spectrometer is $17(L) \times 22$ $(W) \times 16.5 \mathrm{~cm}(H)$ that is approximately five times smaller in volume than the Spex $270 \mathrm{M}$ spectrograph. Further reduction in the size of this instrument is possible by optimizing it with the rest of the remote Raman system. The HoloSpec has a volume holographic transmission (HoloPlex) grating optimized for Raman spectroscopy with 532-nm laser excitation. For our gated CCD detector with $1024 \times 256$ pixels, the grating has a 
spectral band pass of $86.7 \mathrm{~nm}$ or $\sim 2610 \mathrm{~cm}^{-1}$ Stokes-Raman shifted from $532 \mathrm{~nm}$ laser wavelength. Since the wide spectral range of the window, the linear spectral dispersion of the system varies monotonically from $0.08 \mathrm{~nm} \mathrm{pixel}^{-1}$ $\left(2.8 \mathrm{~cm}^{-1}\right.$ pixel $\left.^{-1}\right)$ at the low-wavelength end to $0.06 \mathrm{~nm}$ pixel $^{-1}\left(1.5 \mathrm{~cm}^{-1}\right.$ pixel $\left.^{-1}\right)$ at the high wavelength end. This spectrograph has no moving parts and uses slits of fixed widths $(50,165,250$ $\mu \mathrm{m})$ that require physically changing the slits when needed. With a slit of $50 \mu \mathrm{m}$ width, good quality stand-off Raman spectra of silicates were obtained with medium resolution. A high throughput slit up to $250 \mu \mathrm{m}$ was used for measuring the Raman spectra of glasses or gaseous species at $10 \mathrm{~m}$ distance from the telescope.

\subsection{A continuous wave telescopic Raman spectroscopic system}

A laboratory version of the telescopic Raman spectroscopy system has been designed and assembled using continuous wave (CW) laser excitation (Fig. 3). The Raman spectra recorded with the CW laser and remote Raman system were relatively easy to compare with the Raman spectra of the same minerals and rocks recorded with our multichannel micro-Raman system (for details see

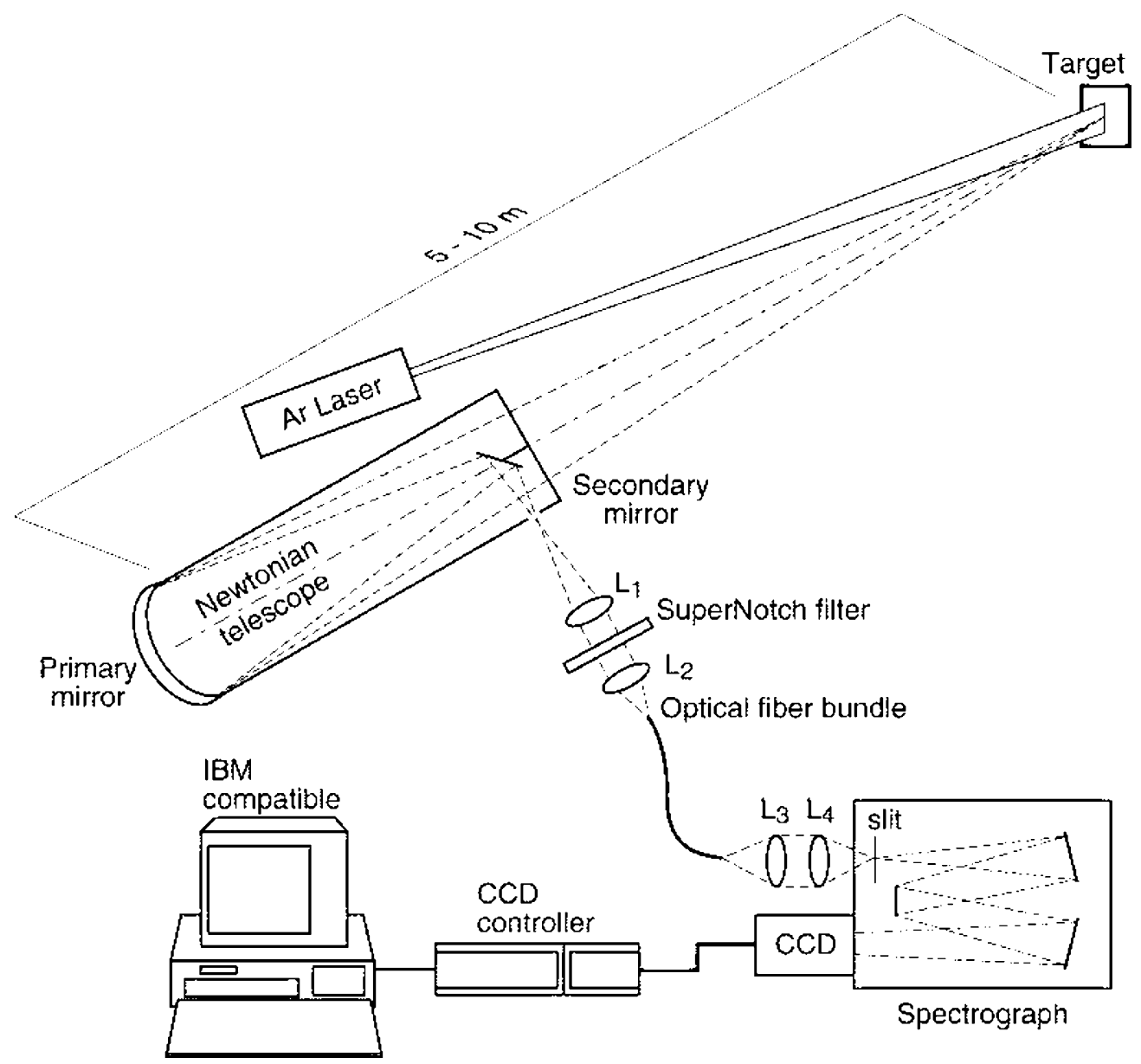

Fig. 3. Schematic diagram of a CW telescopic Raman spectroscopic system developed at the University of Hawaii. 
ref. [38]) as both these systems use $\mathrm{CW}$ lasers as excitation sources and the oblique geometry shown in Fig. 3.

The bench top telescopic Raman system consists of a Spectra Physics Ar-ion laser (Model 165) operated at $488 \mathrm{~nm}$, a $1 / 4 \mathrm{~m}$ imaging spectrograph (CVI Digikrom model DK240, f/3.9, focal length $240 \mathrm{~mm}, 1200 \mathrm{~g} \mathrm{~mm}^{-1}$ grating), a liquid nitrogen cooled Photometrics CCD imager $(1024 \times 256$ pixels), a $10.8 \mathrm{~cm}$ diameter $f / 4.2$ portable Newtonian telescope, and a data collection computer. The telescope primary is a $44.5 \mathrm{~cm}$ focal length parabolic mirror with clear aperture of $10.5 \mathrm{~cm}$. An optical fiber bundle, which is formed into a linear fiber array at one end, is used to connect the telescope to the spectrograph. The linear fiber array of $25,50-\mu \mathrm{m}$ fibers acts as the spectrograph slit dispersing the received light across the entire CCD array. This arrangement of optical fibers helps in increasing the light input into the spectrograph and in matching the $f$-number of the spectrometer with the fiber bundle. A holographic super notch filter (Fig. 3) is adjusted to attenuate the elastically (Rayleigh) scattered and reflected laser light at $488 \mathrm{~nm}$. The CVI spectrograph has a computer controlled, curved entrance slit. The slit width of the spectrograph can be changed from 10 to $3000 \mu \mathrm{m}$ as well as the slit height can be selected from 2 to $20 \mathrm{~mm}$. The spectrometer has maximum resolution of $0.06 \mathrm{~nm}$ with $1200 \mathrm{~g} \mathrm{~mm}^{-1}$ grating. The stray light in the spectrograph is less than $0.01 \%$ at $220 \mathrm{~nm}$ wavelength and even lower in the visible part of the spectrum. The size of this commercial spectrometer is $55(L) \times 24(W) \times 12$ $\mathrm{cm}(H)$.

The laser and telescope are at an oblique angle but were focused upon the same sample spot at a distance of $\geq 4.8 \mathrm{~m}$ from the telescope primary mirror. This geometry minimizes the amount of reflected laser light from the sample surface reaching the telescope. The CCD is cooled to $168 \mathrm{~K}$ with liquid nitrogen. Various combinations of laser power and integration time intervals were investigated to derive a reasonable compromise of SNR and data acquisition efficiency. Current nominal operating specifications are: $130 \mathrm{~mW}$ laser power at the sample and $60 \mathrm{~s}$ integration for light colored samples and $180 \mathrm{~s}$ integration for dark samples.
The system was moved into a larger laboratory that allowed collecting remote Raman data at 9$10 \mathrm{~m}$ from the sample.

\subsection{A combined stand-off LIBS and pulsed Raman spectroscopic (LIBS/Raman) system}

As mentioned in the Section 1, LIBS has been proposed for space exploration. We have explored the use of LIBS combined with pulsed-laser Raman spectroscopy for mineral analysis at a distance of $10 \mathrm{~m}$. We modified our remote pulsed Raman system to collect LIBS data, thus obtaining quantitative values for cation composition in our samples. By analyzing the cation information collected in the LIBS experiment alongside the anion information provided by Raman scattering, a more complete image of the mineral's structure and composition can be obtained.

Fig. 4 shows a schematic representation of the experimental setup for the stand-off LIBS/Raman experiment. A Q-switched Nd:YAG laser (Model DCR-2, from Spectra-Physics, $1064 \mathrm{~nm}, 20 \mathrm{~Hz}$ ), operating at $\sim 200 \mathrm{~mJ}$ per pulse, was focused on the sample approximately $10 \mathrm{~m}$ away creating a plasma spark. The telescope is placed beside the

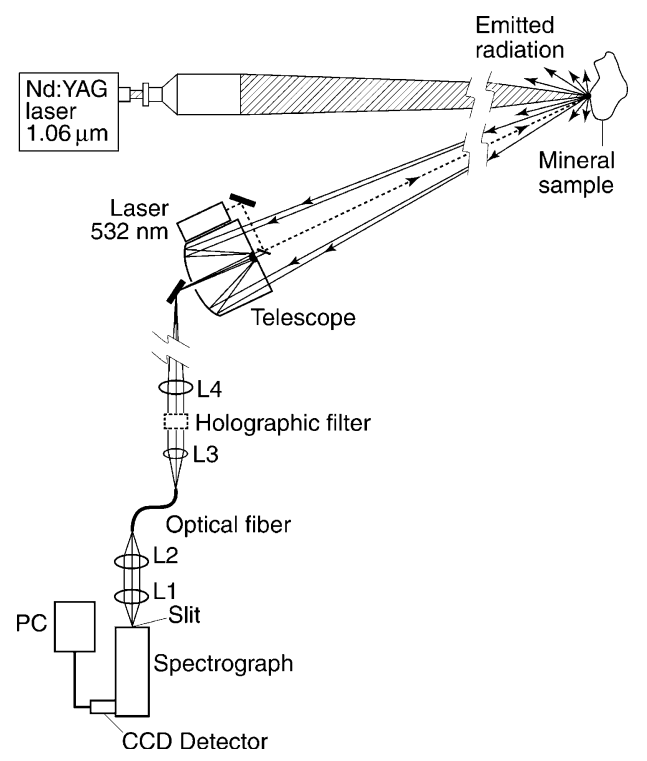

Fig. 4. Schematic representation of the stand-off LIBS/Raman set up. 
laser in order to get as close to the $180^{\circ}$ backscattering geometry as possible.

In the stand-off LIBS experiments, the plasma radiation produced at the mineral surface by the focused $1064 \mathrm{~nm}$ laser are collected and analyzed by our pulsed Raman receiver using the thermoelectrically cooled, gated and intensified CCD (IMax-1024-E) and Spex $270 \mathrm{M}$ spectrograph described in Section 2.1. The holographic notch filter (Fig. 4) is removed during LIBS measurements and the $532 \mathrm{~nm}$ laser is turned off. The LIBS spectra were collected with slit width of $50 \mu \mathrm{m}$. One hundred accumulations were averaged for each spectrum. Excellent quality LIBS spectra of biogenic and abiogenic carbonates, and of olivine samples with varying iron contents were recorded with this system [48]. A radiometrically calibrated broadband light source, a Labsphere ${ }^{\circledR}$ integrating sphere, is used to determine the response function of the system by placing the integrating sphere at the sample location and collecting a spectrum with the identical gain and integration settings used during LIBS measurements. This measurement allows us to calibrate to radiance the observed signal over the entire optical path. By dividing the sample spectrum by the measured response function, the system response effects are removed and the sample spectrum is calibrated directly in spectral radiance units $\left(\mathrm{W} \mathrm{m} \mathrm{m}^{-2} \mathrm{sr}^{-1} \mu \mathrm{m}^{-1}\right)$. For Raman measurements the 1064-nm laser was turned off, the 532-nm holographic notch filter was inserted in the beam path, and the mineral and rocks were excited with 532-nm pulsed laser and the scattered radiation analyzed as discussed before in Section 2.1. This system thus allows measurement of the Raman and LIBS spectra at the same location at the mineral surface at a distance of $10 \mathrm{~m}$. It should be noted, however, that the sampling diameter for LIBS is much smaller $(<1 \mathrm{~mm}$ diameter) than the sampling diameter in Raman experiment (a few cm diameter) at $10 \mathrm{~m}$ distance.

\section{Samples}

For evaluating the performance of the stand-off Raman systems, analytical grade benzene was used as a Raman standard. For measurements at a distance of about $10 \mathrm{~m}$, the benzene sample was contained in a glass bottle of $3 \mathrm{~cm}$ diameter and $6.5 \mathrm{~cm}$ high. For remote Raman spectra of benzene at $\sim 66 \mathrm{~m}$, the sample was contained in a square shape flask (100 ml, Kimax class A). The rock-forming mineral samples were purchased from Ward's Natural Science Establishment, Inc., Rochester, New York. These samples were used without any polishing or cutting.

The rock originally labeled as forsterite contains fine-grained, light greenish color minerals from Jackson County, North Carolina, USA. The electron microprobe analysis of the sample found it to be a magnesium-rich olivine $\left(\mathrm{Fo}_{92}\right),(92 \%$ forsterite $\left(\mathrm{Mg}_{2} \mathrm{SiO}_{4}\right)$, and $8 \%$ fayalite $\left.\left(\mathrm{Fe}_{2} \mathrm{SiO}_{4}\right)\right)$. A number of mineral/rock samples used in the present work were from various geological locations within the United States, including a polycrystalline milky quartz sample from Fremont County, Colorado, olivine $\left(\mathrm{Fo}_{90}\right)$ crystals from the Island of Hawaii, plagioclase of labradorite variety from Essex County, New York, and a polycrystalline microcline-containing rock from Crystal Peak, Colorado. The marble sample has large crystals of calcite and was from Butte, Montana. The polycrystalline dolomite sample was from Bamble, Norway.

\section{Results and discussion}

\subsection{Spectral measurements with the stand-off pulsed Raman prototype}

Typical spectra of silicate minerals recorded with the stand-off pulsed Raman laboratory system at a distance of $10 \mathrm{~m}$ are shown in Figs. 5 and 6, where the strong fingerprint Raman lines of olivine (821 and $852 \mathrm{~cm}^{-1}$ ), feldspar (475 and 503 $\mathrm{cm}^{-1}$ ), and $\alpha$-quartz $\left(464 \mathrm{~cm}^{-1}\right)$ are well resolved. In Fig. 5, the strong bands of four-membered ring of $\mathrm{TO}_{4}$ (where $\mathrm{T}=\mathrm{Si}$ or $\mathrm{Al}$ ) are clearly visible in the spectra of microcline and plagioclase containing rocks $[39,40]$. In the spectrum of plagioclase sample (Fig. 6), the presence of a weak high frequency doublet at lower frequencies (993 and $1082 \mathrm{~cm}^{-1}$ ) as compared with the corresponding 


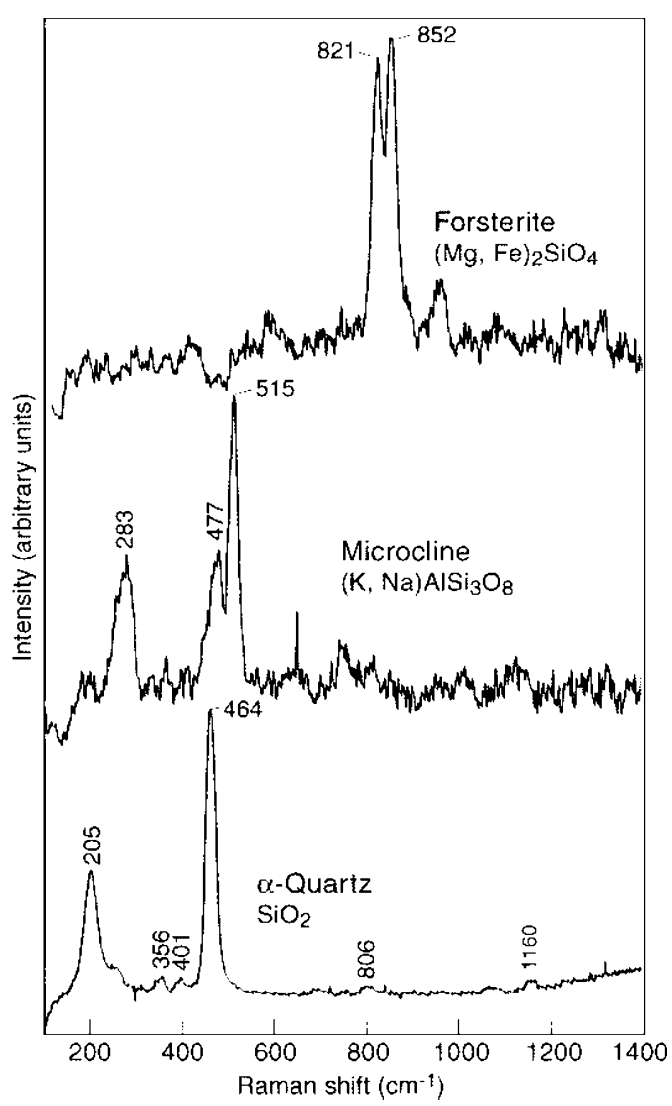

Fig. 5. Remote Raman spectra of silicate minerals measured at distance of $10 \mathrm{~m}$ from the telescope. Excited with a pulsed 532$\mathrm{nm}$ laser, $20 \mathrm{~Hz}$, and pulse energy of $35 \mathrm{~mJ}$ per pulse. The spectra were averaged over 3000 laser pulses $(t=150 \mathrm{~s})$.

bands (1012 and $1127 \mathrm{~cm}^{-1}$ ) reflects higher $\mathrm{Al} / \mathrm{Si}$ ratio in the plagioclase crystals [40]. In the case of pyroxene the fingerprint Raman bands are observed at 660 and $1010 \mathrm{~cm}^{-1}$, corresponding to symmetrical stretching of bridging and non-bridging oxygen of the silicate chain, respectively $[10,15]$.

The long-range capability of the pulsed Raman system is demonstrated by recording the room temperature Raman spectra of dolomite, $\mathrm{CaMg}$ $\left(\mathrm{CO}_{3}\right)_{2}$, and of liquid benzene, $\mathrm{C}_{6} \mathrm{H}_{6}$, at a distance of $66 \mathrm{~m}$ from the telescope (Figs. 7 and 8, respectively) at an outdoor location. For these measurements, the CCD was gated for $15 \mathrm{~ns}$ and synchronized with laser pulses to minimize interference from ambient light. In the dolomite spectra

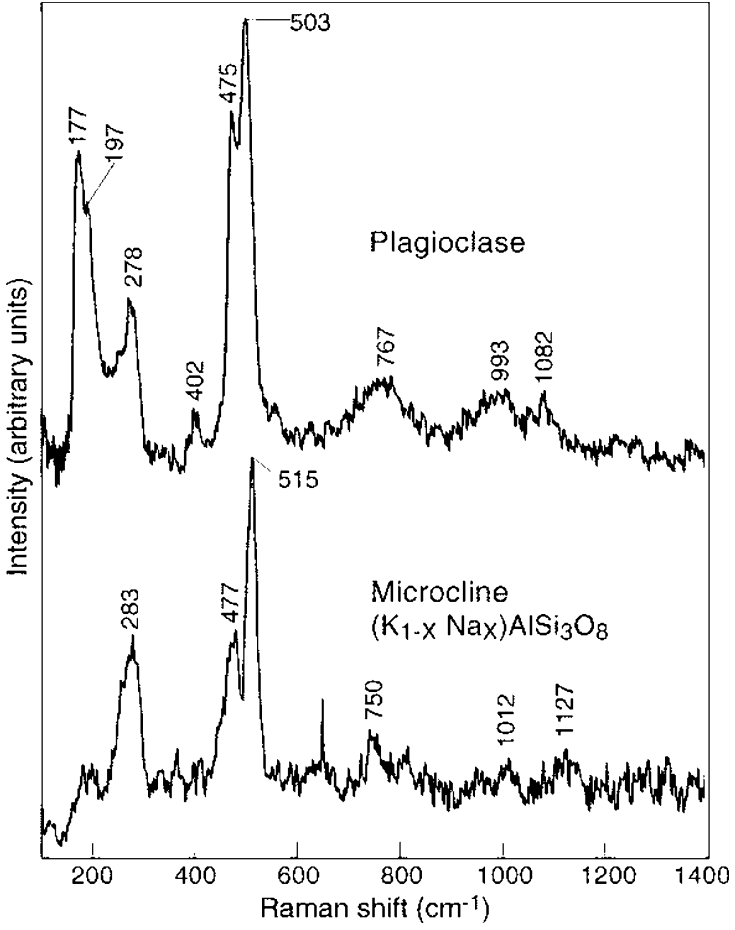

Fig. 6. Remote Raman spectra of plagioclase and microcline containing rock measured at distance of $10 \mathrm{~m}$ from the telescope. Laser $532 \mathrm{~nm}, 35 \mathrm{~mJ}$ per pulse; spectra averaged over 1200 laser pulses.

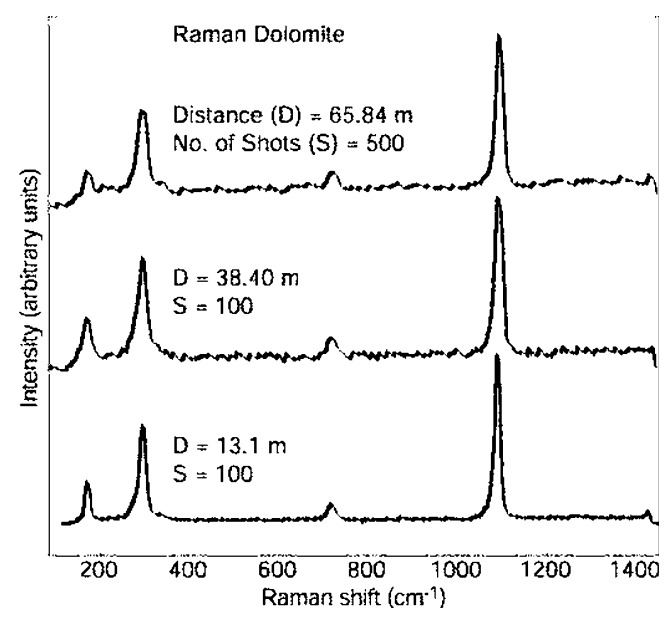

Fig. 7. Parts of pulsed-Raman spectra of dolomite recorded at various distances. The spectra at 13.1, 38.4 and $65.84 \mathrm{~m}$ were recorded by binning the ICCD along the wavenumber axis with 1, 2 and 3-pixels, respectively. Laser power was $35 \mathrm{~mJ}$ per pulse at $532 \mathrm{~nm}$. 


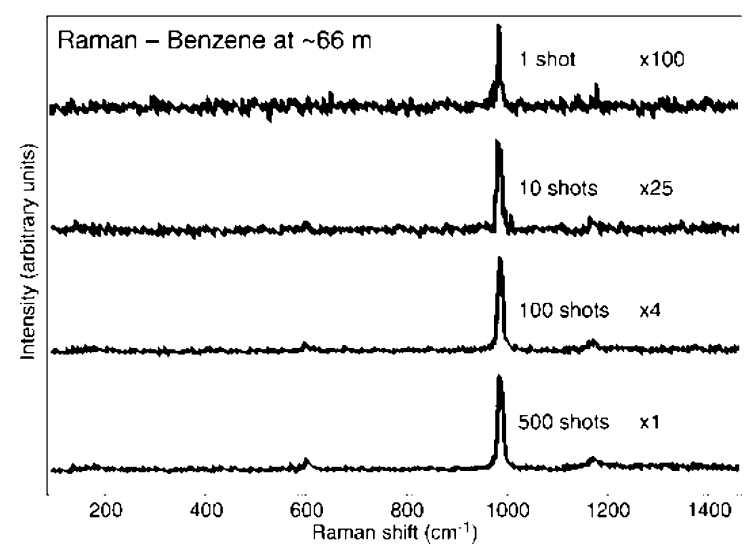

Fig. 8. Remote Raman spectra of benzene measured at distance of $66 \mathrm{~m}$ with varying number of laser shots $(S)$. The Raman spectrum of benzene can be obtained with a single $35-\mathrm{mJ}$ pulse from the laser at a distance of $66 \mathrm{~m}$. Laser excitation $35 \mathrm{~mJ}$ per pulse, $532 \mathrm{~nm}, 20 \mathrm{~Hz}$.

(Fig. 7), the upper trace at $D=66 \mathrm{~m}$ was recorded with CCD binning set at $3 \times 256$ pixels, the middle trace at $D=38 \mathrm{~m}$ was recorded with CCD binning set at $2 \times 256$ pixels, and the bottom trace at $D=$ $13 \mathrm{~m}$ was recorded with standard CCD binning set at $1 \times 256$ pixels in each channel.
In these 66-m stand-off Raman spectra the strong fingerprint bands of symmetric stretching modes of carbonate ions and benzene rings, respectively, at 1097 and $991 \mathrm{~cm}^{-1}$, are measured with good SNR using integration time of $\leq 25 \mathrm{~s}$. The low-frequency lattice modes in the spectrum of dolomite appear at 175 and $299 \mathrm{~cm}^{-1}$, which are higher than the frequencies of the corresponding lattice modes of marble, respectively, at 156 and $281 \mathrm{~cm}^{-1}[10,41]$. The differences in the frequencies of the sharp lattice Raman lines of these carbonates are sufficient for identifying these minerals on a planetary surface.

\subsection{Spectral measurements with the field-portable pulsed Raman system}

Fig. 9 illustrates the Raman spectra of benzene in liquid and vapor phase at room temperature recorded with the field portable pulsed Raman system at various slit widths at a stand-off distance of $10 \mathrm{~m}$. The spectrum of liquid benzene, recorded with slit width of $50 \mu \mathrm{m}$ and $1 \mathrm{~s}$ integration time, shows good SNR for the fingerprint $\mathrm{A}_{1 \mathrm{~g}}$ mode of benzene ring at $992 \mathrm{~cm}^{-1}$. The weak bands at 1585

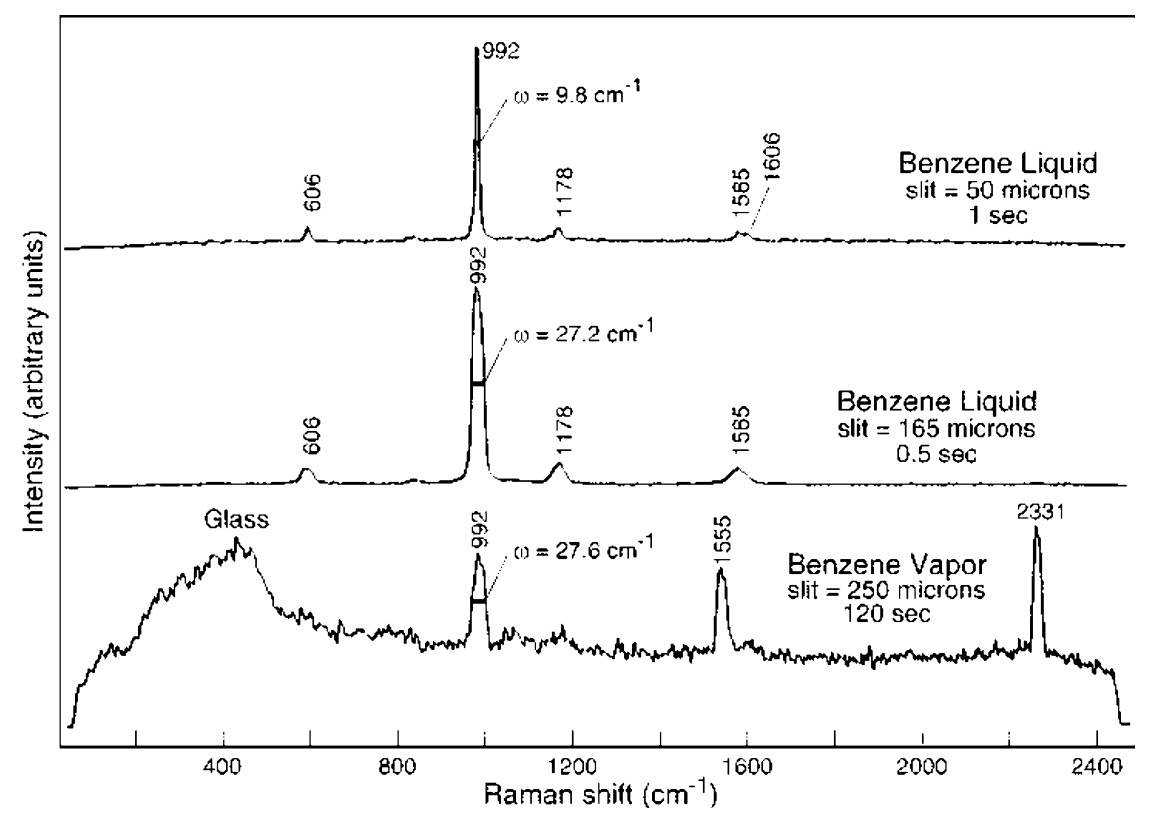

Fig. 9. Raman spectra of benzene liquid and vapors recorded with various slit widths as marked on the spectra using field portable pulsed-remote Raman spectroscopic system equipped with HoloSpec spectrometer. Laser excitation $532 \mathrm{~nm}, 35 \mathrm{~mJ}$ per pulse, $20 \mathrm{~Hz}$. 
and $1606 \mathrm{~cm}^{-1}$ in the double, corresponding to $\mathrm{Eg}^{+}$modes, are well resolved, and additional weak bands of benzene at 606 and $1178 \mathrm{~cm}^{-1}$, originating from $\mathrm{Eg}^{+}$modes [42], are clearly visible (Fig. 9). The frequencies of the benzene bands are within $\pm 1 \mathrm{~cm}^{-1}$ of values reported in the literature [42]. It is interesting to note that in the Raman spectra of benzene vapors (Fig. 9), recorded from the vapor sample confined in a Pyrex beaker at room temperature and $1 \mathrm{~atm}$ at a distance of $10 \mathrm{~m}$ from the telescope, we clearly see the symmetric stretching band of the benzene ring at $992 \pm 1 \mathrm{~cm}^{-1}$, and the symmetric stretching bands of oxygen $\left(1555 \pm 1 \mathrm{~cm}^{-1}\right)$ and nitrogen $\left(2331 \pm 1 \mathrm{~cm}^{-1}\right)$ from the air [33] along with a weak and broad band at $\sim 448 \pm 5 \mathrm{~cm}^{-1}$ from the Pyrex glass of the container. With the fieldportable system (Fig. 2), we have measured the Raman spectra of silica glass at $10 \mathrm{~m}$ stand-off distance with $30 \mathrm{~s}$ integration time $(600$ laser shots). The spectrum of silica glass is comparable in quality to that observed with the laboratory Raman spectrographs and CW laser [43]. Evidently, the system has the sensitivity to detect the silicate minerals in crystalline, disordered, and amorphous phases. Detection of fingerprint spectra of disordered and glassy silicate with the standoff Raman system could be an important capability as the disordered and amorphous phases of mineral compositions could be formed on planetary surfaces as a result of shock metamorphism, rapid cooling of magmatic melts, or bio-activity.

\subsection{Spectral measurements with the $C W$ telescopic Raman spectroscopic system}

With the stand-off CW telescopic Raman system a great deal of effort was put into developing the data acquisition protocol and data reduction methodology in order to quantify the Raman data. Adapting standard radiometric imaging techniques, all data are acquired in full-CCD image mode. This allows application of standard image processing methods to correct for background (read-out noise dominated), bad pixels, cosmic ray hits, and system response. Flat fielding of the image is accomplished by using a radiometrically calibrated source, the Labsphere integrating sphere, which also allows us to calibrate the observed signal to radiance. The sequence of steps involved in the data acquisition and reduction process is illustrated in Fig. 10. A dark image (top frame in Fig. 10) is acquired and subtracted from both the sample spectral image (Fig. 10a) and the flat-field image (Fig. 10b). The response function of the system is calculated from the flat-field image on a line-by-line basis and divided into the darksubtracted sample image to produce the flatfielded, calibrated sample image (Fig. 10c) in spectral energy units $\left(\mathrm{J} \mathrm{m}^{-2} \mathrm{sr}^{-1} \mu \mathrm{m}^{-1}\right)$ or in radiance $\left(\mathrm{W} \mathrm{m}^{-2} \mathrm{sr}^{-1} \mu \mathrm{m}^{-1}\right)$ for $1 \mathrm{~s}$ integration time.

The final telescopic Raman spectrum is then produced by averaging the entire image along the slit direction, for significantly improved SNR [9]. Wavelength calibration is achieved by performing a quadratic fit to the derived spectrum of a sample with well-known spectral peaks, usually calcite or

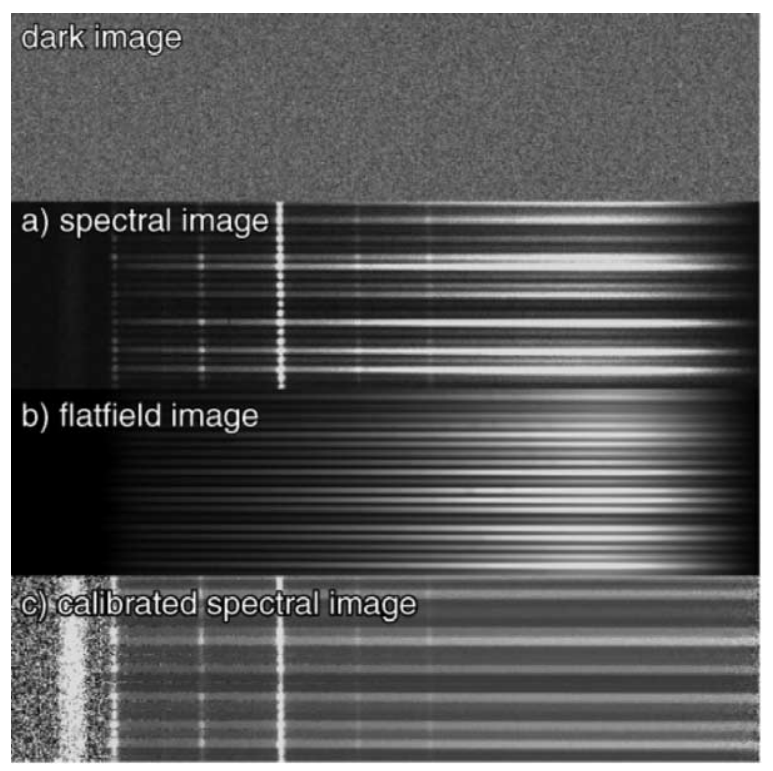

Fig. 10. A CW dark image (top frame) is acquired and subtracted from both the calcite spectral image (a) and the flat field image (b). The response function of the system is calculated from the flat field image on a line-by-line basis and divided into the dark subtracted sample image to produce the flat-fielded, calibrated sample image (c) in spectral energy units $\left(\mathrm{J} \mathrm{m}^{-2} \mathrm{sr}^{-1} \mu \mathrm{m}^{-1}\right)$ or spectral radiance units $\left(\mathrm{W} \mathrm{m} \mathrm{m}^{-2} \mathrm{sr}^{-1}\right.$ $\mu \mathrm{m}^{-1}$ ) for $1 \mathrm{~s}$ integration time. Laser CW Ar-ion, $488.0 \mathrm{~nm}$, $150 \mathrm{~mW}$. 
Spectralon. Fig. 11(a-c) illustrates the data reduction and calibration process in the spectral domain, although all steps are actually performed in the image domain.
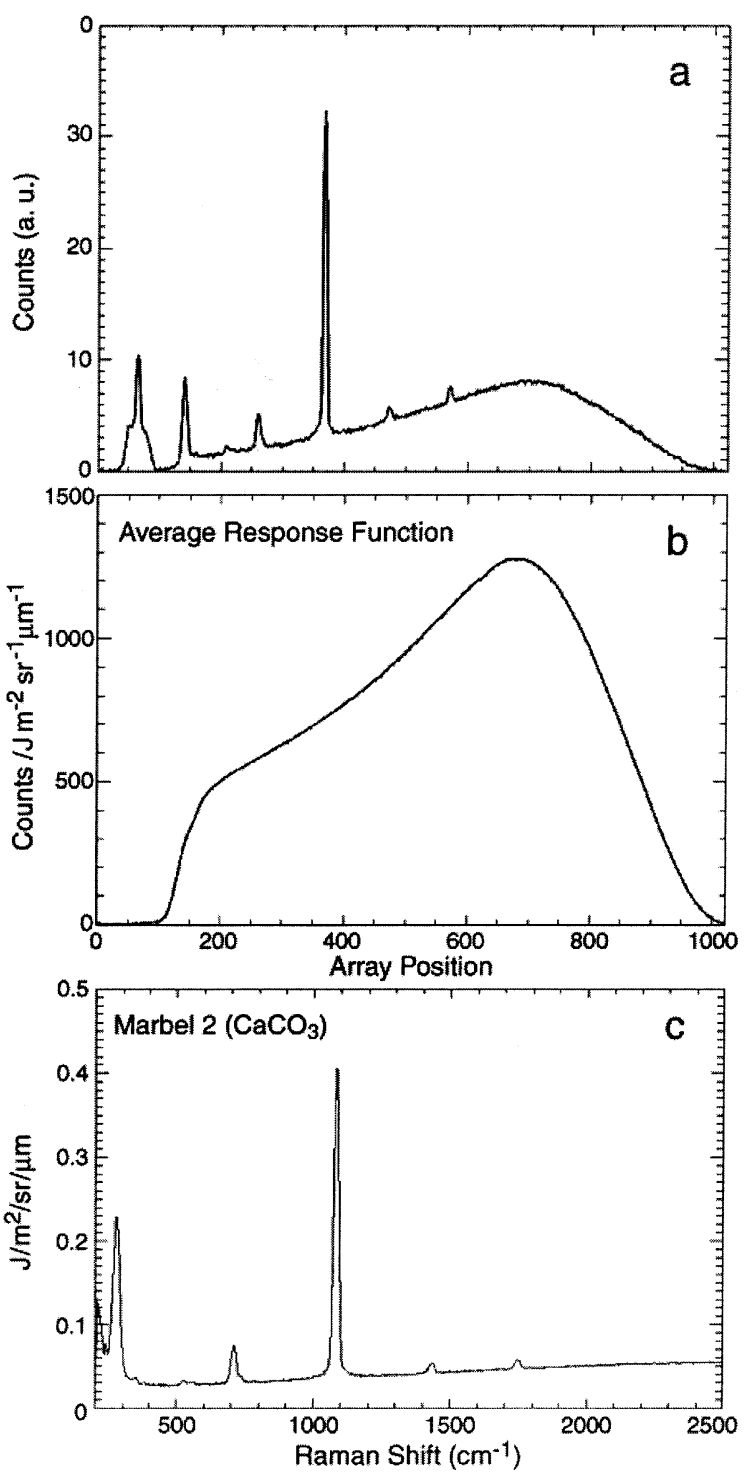

Fig. 11. CW stand-off Raman spectra of calcite converted from image domain (Fig. 10) to spectral domain showing calibration steps. Each plot is annotated. Between curves (a) and (b), and the wavelength calibration steps to convert array position to Raman shift (plot c) are not shown. Experimental parameters were the same as in Fig. 10.

\subsubsection{Raman intensity calibration}

As noted in the previous subsection, remote Raman spectra are calibrated to spectral radiance, $L(\lambda)\left(\mathrm{W} \mathrm{m}^{-2} \mathrm{sr}^{-1} \mu \mathrm{m}^{-1}\right)$, by observing a known, traceable spectral source (the Labsphere integrating sphere) and calculating the system response function. In order to determine the Raman efficiency for each set of measurements, the laser power at the sample needs to be measured. The current experimental setup assumes the following nominal parameters:

Laser power $(P)$

Laser wavelength

Laser spot size

Laser spot area $\left(A_{\text {las }}\right)$

Distance from target to

telescope primary $(r)$

Telescope clear aperture $\quad 105 \mathrm{~mm}$

Integration time $(t)$

Laser energy during time $t$

$\left(E_{0}=P \times t\right)$

At a distance of $r(5.1 \mathrm{~m})$, one steradian covers an area of $r^{2}\left(26.01 \mathrm{~m}^{2}\right)$, and the telescope field of view subtends a solid angle of $3.29 \times 10^{-4}$ steradian $\left(\theta_{\text {solid }}\right)$. Pixel bandwidth $(\lambda)$ is derived from the wavelength calibration of a known sample $\left(9.1 \times 10^{-2} \mathrm{~nm}\right)$. The Raman scattered energy $\left(E_{\mathrm{r}}\right)$ received from the target in the atmosphere with transmission $T$ is given by:

$E_{\mathrm{r}}=L(\lambda) \cdot t \cdot A \cdot \theta_{\text {solid }} \cdot \Delta \lambda$

And the Raman scattering efficiency is defined as:

$R_{\text {eff }}=E_{\mathrm{r}} / E_{0}$

As is often the case with natural samples, fluorescence signal often interferes with the Raman signal of interest. Where the fluorescence is significant, the background is removed from the spectrum automatically by evenly re-sampling the 1024 element spectral array to the minimum value of every 20th point; applying a three-element median filter to eliminate points which happen to fall on a peak, then interpolating this sparse array back to the original spectrum length; subtracting the new smoothed array from the original spectrum, and adding back the minimum noise floor 
value to avoid artificially applying an offset of the spectrum. The spectrum of a calcite crystal in random orientation expressed as a function of Raman scattering efficiency ( $\left.R_{\text {eff }}\right)$ is illustrated in Fig. 12. The background fluorescence has been removed from the calcite spectrum.

In the case of benzene, the knowledge of laser spot size, and volume sampled allowed us to calculate the differential scattering cross section $(\sigma)$ of the benzene molecule in the liquid phase. The following list compares our results with previously published $\sigma$ values for benzene (normalized to $488-\mathrm{nm}$ laser excitation wavelength) showing good agreement.

$\sigma=(35.33 \pm 4.32) \times 10^{-30} \quad$ (present work)

$\sigma=(37.60 \pm 4.6) \times 10^{-30}$

Eysel et al. [44].

$\sigma=(35.83 \pm 5.37) \times 10^{-30}$

Ray et al. [45].

\subsubsection{Signal to noise ratio (SNR) and fluorescence}

In order to evaluate the $\mathrm{CW}$ telescopic Raman system's noise and performance, a series of 20 spectra were obtained on a sample of washed olivine grains in the size fraction range of 500$1000 \mu \mathrm{m}$. The data were acquired at a distance of

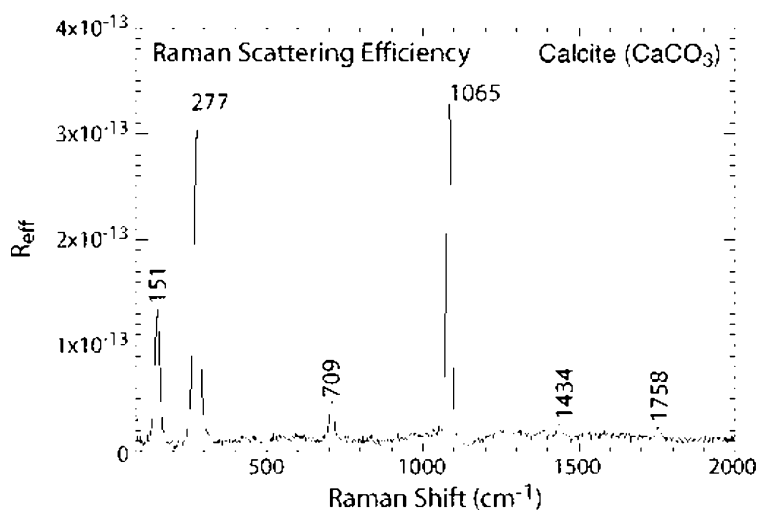

Fig. 12. Raman spectrum of a calcite crystal in random orientation at $5.1 \mathrm{~m}$ from the telescope Raman scattering calibrated in terms of effective Raman efficiency as a function of Stokes-Raman shift. Laser CW Ar-ion, $488 \mathrm{~nm}, 250 \mathrm{~mW}$, and integration time $15 \mathrm{~s}$.

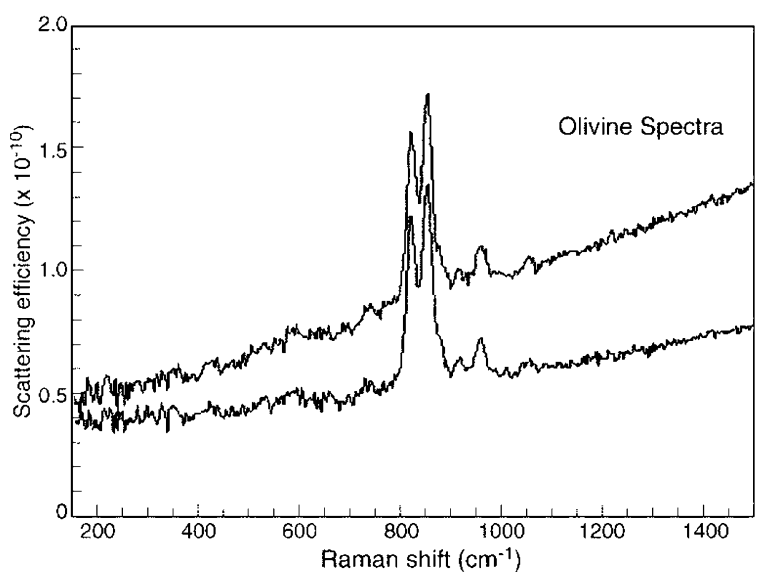

Fig. 13. Telescopic Raman spectra of olivine measured as a function of exposure to laser light for a given time $(\tau)$. Distance, $5.1 \mathrm{~m}$. Laser CW, $488 \mathrm{~nm}, 0.25 \mathrm{~W}$, integration time $t=60 \mathrm{~s}$. Top curve recorded at $\tau=0$; bottom curve at $\tau=20 \mathrm{~min}$.

$5.1 \mathrm{~m}$, with an integration time of $60 \mathrm{~s}$ each, and at-target laser power of $250 \mathrm{~mW}$ at $488 \mathrm{~nm}$. This particular olivine sample exhibited moderate fluorescence, which declined with exposure to $488 \mathrm{~nm}$ laser light through the duration of the experiment. Fig. 13 shows the resulting scattering efficiency spectra of olivine grains. The first olivine spectrum (upper curve, Fig. 13) and the last of the 20th spectrum of the series collected after $20 \mathrm{~min}$ of laser light exposure (lower curve, Fig. 13) show the characteristic olivine Raman doublet near 850 $\mathrm{cm}^{-1}$, but they also exhibit a reduction in the fluorescence background with exposure time. Blue lasers are known to be more efficient than red ones in minimizing fluorescence from solids [46]. Fig. 14 shows a plot of the peak height of $853 \mathrm{~cm}^{-1}$ band without (upper curve with square) and with (lower curve with triangles) fluorescence background correction. The upper curve in Fig. 14 shows that the uncorrected peak height of the 853 $\mathrm{cm}^{-1}$ band underwent exponential decrease because of a decrease in fluorescence emission. The lower curve in the plot (Fig. 14) shows the same peak heights after application of the automatic baseline removal. The slight negative slope of the straight-line fit is an artifact of the baseline removal algorithm. The SNR for these olivine spectra was approximately 100 . 


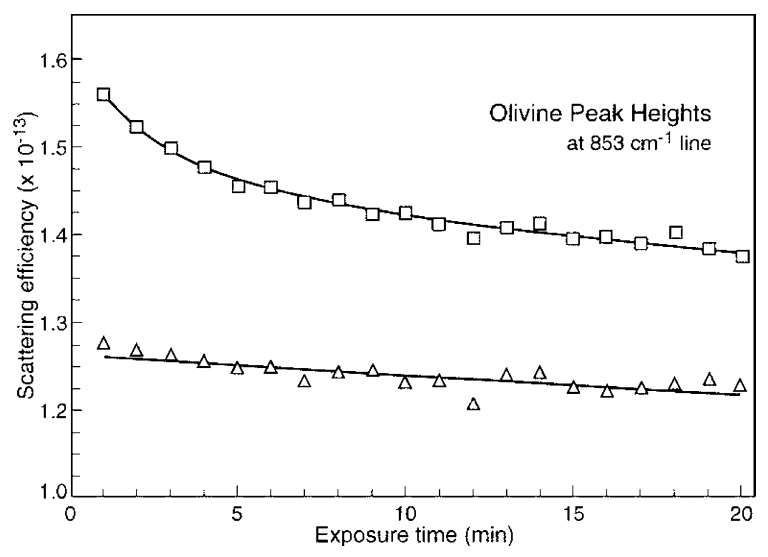

Fig. 14. Plot of uncorrected intensity of the olivine band at 850 $\mathrm{cm}^{-1}$ illustrates the effect of fluorescence quenching as a function of exposure to laser light at $488 \mathrm{~nm}$ (top curve marked with squares). Bottom curve marked with triangles shows variation in the intensity of the band at $850 \mathrm{~cm}^{-1}$ after base line corrections.

Quality of the wavelength calibration, and hence the Raman shift calibration, was evaluated with the $5 \mathrm{~m}$ range data collected on a Spectralon (Teflon) target with at-target power levels of 100, 150 , and $250 \mathrm{~mW}$ and three different integration times (30, 60, and $180 \mathrm{~s})$. Over the Stokes-Raman shifted region of interest for silicate and other common rock-forming minerals $\left(100-1500 \mathrm{~cm}^{-1}\right)$, the error of the calibration fit is less than $1 \mathrm{~cm}^{-1}$.

\subsubsection{Baseline Raman spectra of minerals with micro-Raman spectrometer}

4.3.3.1. Excitation with various laser wavelengths. In order to evaluate various scattering geometries, we measured micro-Raman spectra of a large collection of common rock-forming minerals with our existing multichannel micro-Raman system. This micro-Raman system is described elsewhere [38] and is capable of operating both in 180 and $135^{\circ}$ scattering geometries. The baseline micro-Raman data of rocks and minerals allowed us to compare the results with those obtained with the CW telescopic Raman system. Additionally, these micro-Raman data were collected using $\mathrm{CW}$ laser wavelengths at $457.9 \mathrm{~nm}$ (violet), $488 \mathrm{~nm}$ (blue), $532 \mathrm{~nm}$ (green), and $647.1 \mathrm{~nm}$ (red) to determine the optimum excitation to reduce the effects of sample fluorescence. Iron oxide (e.g. magnetite, hematite, etc.) samples were found to yield Raman spectra with high signal to background ratio when excited with the red laser radiation with 5-7 $\mathrm{mW}$ power at the sample (Fig. 15). On the other hand, olivine, pyroxene, and some plagioclase samples yield best Raman spectra under short wavelength excitation and do not show any appreciable heating when excited with $50 \mathrm{~mW}$ of violet, blue or green laser radiation.

These results show that for the remote Raman spectroscopic instrument availability of laser sources with two excitation wavelengths (green and red) will allow sensitive detection of most of the minerals. The availability of diode lasers at red wavelength and diode pumped solid-state green lasers with small size, low weight, and low power consumption will allow development of a compact remote Raman instrument for landers and rovers. The use of a CW laser will restrict the operation of

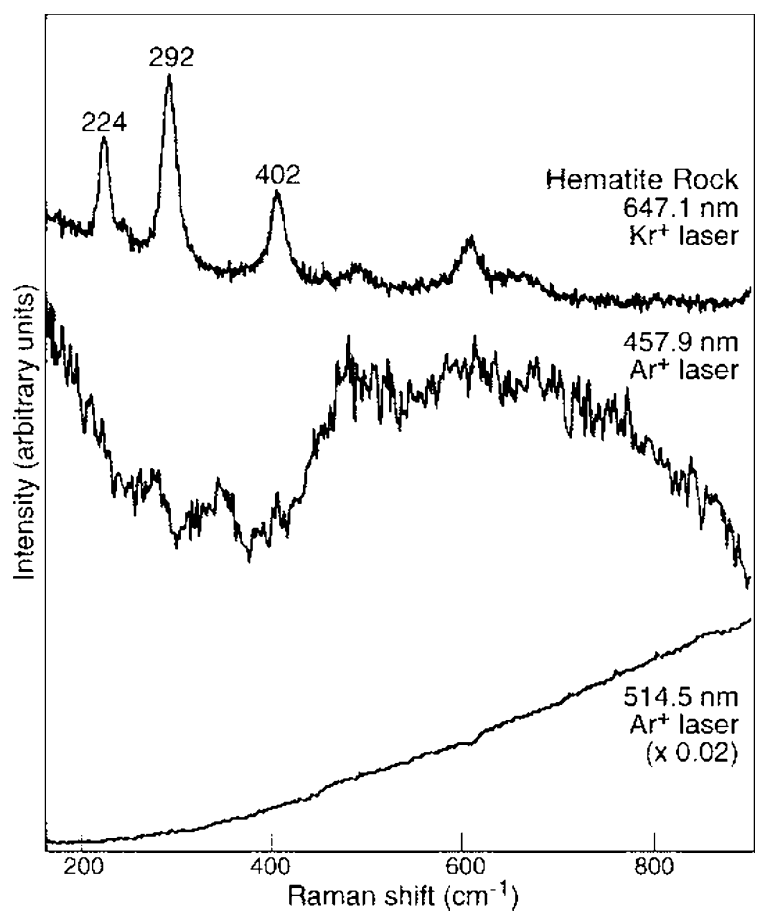

Fig. 15. Micro-Raman spectra of a Hematite rock measured with various lines of $\mathrm{CW}$ Ar-ion and $\mathrm{Kr}$-ion laser excitations. These spectra were measured with the University of Hawaii's multi-channel micro-Raman spectrometer. 
the stand-off Raman system during night or under cloud cover and low ambient light conditions.

\subsubsection{Effect of grain size and mixtures on the}

Raman spectra. Since multiple mineral grains are illuminated and observed for each stand-off $\mathrm{Ra}-$ man measurement, initial experiments have been conducted with the remote $\mathrm{CW}$ telescopic Raman system to determine the effect of grain size on Raman spectra. The Raman spectra of olivine sample (grain size $<63-1000 \mu \mathrm{m}$ ) show distinct and narrow characteristic peaks of ortho-silicate units in the $800-900 \mathrm{~cm}^{-1}$ fingerprint region. For the grain size below $60 \mu \mathrm{m}$, the intensities of the characteristic bands show decrease in relative intensity due to multiple scattering loss of Raman signal. The position of the characteristic Raman bands of olivine, however, remains the same for all the samples. Similar Raman measurements were carried out for $\alpha$-quartz grains with grain size in the range of sub-micron to $250 \mu \mathrm{m}$ [47]. In the Raman spectrum of the quartz grains of $11-20 \mu \mathrm{m}$ diameter, the strongest symmetric stretching mode of bridging oxygen $\left(v_{\mathrm{S}}(\mathrm{Si}-\mathrm{O}-\mathrm{Si})\right)$ of six-member ring of $\mathrm{SiO}_{4}$ tetrahedra appears at $464 \mathrm{~cm}^{-1}$ and has the same line width $\left(7.5 \mathrm{~cm}^{-1}\right)$ as the bulk material. In the sub-micron to $11 \mu \mathrm{m}$ size grains of $\alpha$-quartz, the $v_{\mathrm{S}}(\mathrm{Si}-\mathrm{O}-\mathrm{Si})$ band remains distinct but shows a small $\left(\sim 0.5 \mathrm{~cm}^{-1}\right)$ negative shift and a small increase in band width $\left(\sim 0.5 \mathrm{~cm}^{-1}\right)$. In the spectra of aggregated grains the intensity of the $v_{\mathrm{S}}(\mathrm{Si}-\mathrm{O}-\mathrm{Si})$ drops significantly and could be as low as $7 \%$ of the $v_{\mathrm{S}}(\mathrm{Si}-\mathrm{O}-\mathrm{Si})$ band intensity observed in the spectrum of $250-\mu \mathrm{m}$ quartz grains. This drop in the intensity of the $v_{\mathrm{S}}(\mathrm{Si}-\mathrm{O}-\mathrm{Si})$ band of fine-grained aggregates is due to losses caused by multiple scattering between the grains. Similar effect has been observed previously in the microRaman spectrum of calcite and olivine grains [48] and in the stand-off $\mathrm{CW}$ telescopic spectra of olivine samples. The degree of laser-induced heating was also found to be significant in the microRaman spectra of aggregated $\alpha$-quartz grains of sub- $\mu \mathrm{m}$ to $11-\mu \mathrm{m}$ sizes when medium laser power of $150 \mathrm{~mW}$ was focused to a spot of $10 \mu \mathrm{m}$ diameter. In the case of remote Raman systems, since the laser beam is not focused, the effect of laser-induced heating is not expected to be a serious problem for non-absorbing samples. The drop in Raman intensity with decreasing grain size will make it difficult to make quantitative intensity measurements. The fingerprint frequency of minerals remains distinct even in sub-micron grains and can be used for mineral identification in finegrained rocks $[47,48]$.

\subsection{Combined LIBS and Raman stand-off measurements}

Selected LIBS spectra collected in the region around $530 \mathrm{~nm}$ (Fig. 15) show a strong $\mathrm{Ca}(\mathrm{I})$ atomic emission line at $534.94 \mathrm{~nm}$ (Fig. 16, calcite). Three strong emission lines of $\mathrm{Ca}(\mathrm{I})$ are visible in the 526-528 nm region of the spectrum. Five lines are expected in this region, but these lines were not resolved. Also, there is a $\mathrm{Ca}$ line at $518.9 \mathrm{~nm}$. Three $\mathrm{Mg}$ emission lines appear at $516.73,517.26$, and $518.36 \mathrm{~nm}$ (Fig. 16, magnesite). We chose to evaluate the $\mathrm{Mg}$ data at 517.26 $\mathrm{nm}$, as this line is well resolved. The dolomite spectrum (Fig. 16, dolomite) is used to adjust for the strength of the individual emission lines, as the ratio of $\mathrm{Ca}$ to $\mathrm{Mg}$ in dolomite is $1: 1$. In this way, we can determine that the ratio of the $\mathrm{Ca}$ to $\mathrm{Mg}$ in our pink coral sample (Fig. 16, pink coral) is

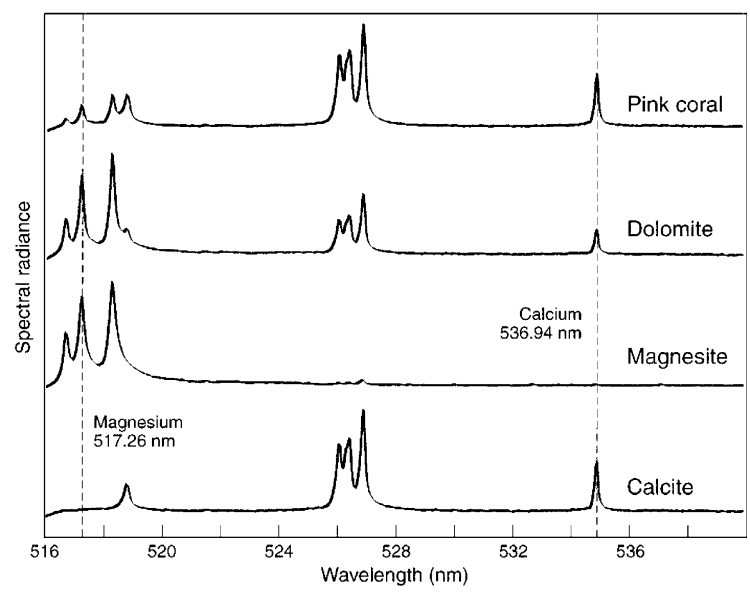

Fig. 16. Portions of LIBS spectra of biogenic (pink coral) and abiogenic carbonates recorded with a combined LIBS/Raman system at a stand-off distance of $10 \mathrm{~m}$. The lines at 517.3 and $534.9 \mathrm{~nm}$ are used to determine $\mathrm{Mg}$ and $\mathrm{Ca}$ concentrations, respectively. Laser $1060 \mathrm{~nm}, 100 \mathrm{~mJ}$ per pulse, $20 \mathrm{~Hz}$, slit 50 micrometer; measurement time $5 \mathrm{~s}$. 
89.3:10.7 $\mathrm{mol} \%$. This value of $\mathrm{Ca} / \mathrm{Mg}$ ratio for pink coral is within $\pm 0.5 \%$ to the value of $90.1: 9.9$ mol\% measured by electron microprobe [27]. We did the same LIBS experiment on silicate samples including olivine along the join $\mathrm{Mg}_{2} \mathrm{SiO}_{4}\left(\mathrm{Fo}_{100}\right)$ $\mathrm{Fe}_{2} \mathrm{SiO}_{4}\left(\mathrm{Fay}, \mathrm{Fo}_{0}\right)$, as well as on gypsum and white coral. Fig. 17 shows parts of typical LIBS spectra in the $515-555 \mathrm{~nm}$ spectral region of an iron foil and two olivine samples. The analysis of the Fe content in magnesium-rich olivine (Fo 90, Fo 92) samples was carried out using atomic emission lines at $517.26 \mathrm{~nm}$ from $\mathrm{Mg}(\mathrm{I})$ and $526.95 \mathrm{~nm}$ from $\mathrm{Fe}(\mathrm{I})$ from the calibrated LIBS spectra of these samples. The Fe contents of these minerals determined with remote LIBS are in agreement (within $\pm 0.5 \%$ ) with the electron microprobe analysis of the respective samples [49].

In the Raman spectra of all the four carbonate samples used for LIBS experiments, Raman bands at $\sim 1085 \mathrm{~cm}^{-1}$ are observed (Fig. 18). This band

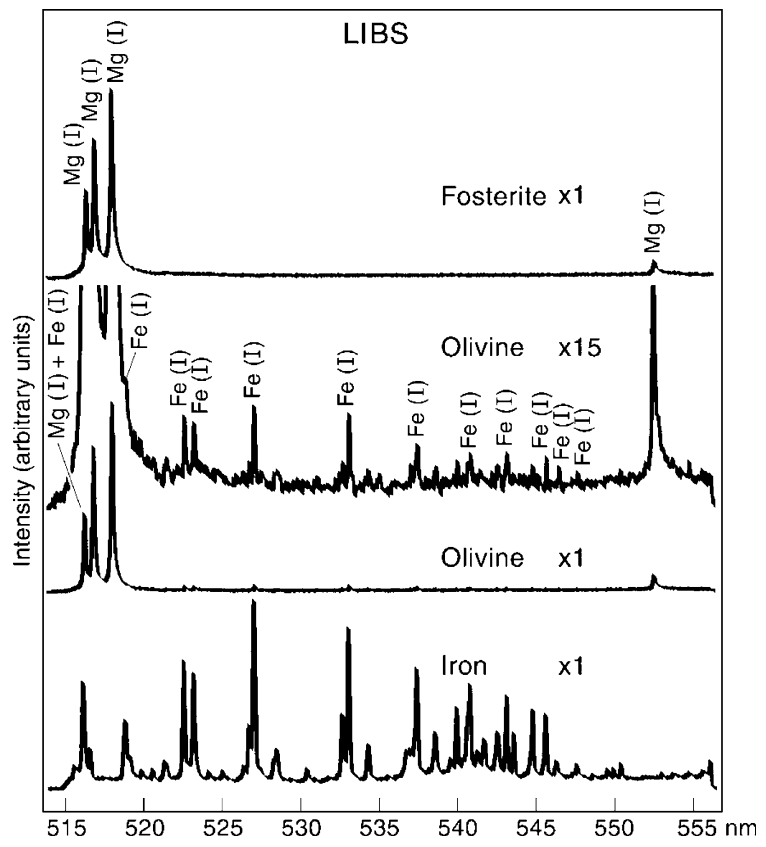

Fig. 17. Portions of LIBS spectra of an iron metal foil, two olivines containing rocks and synthetic forsterite $\left(\mathrm{Fo} ; \mathrm{Mg}_{2} \mathrm{SiO}_{4}\right)$ crystal recorded with a combined LIBS/Raman system at a stand-off distance of $10 \mathrm{~m}$. The lines at 517.3 and $526.95 \mathrm{~nm}$ are used, respectively, to determine $\mathrm{Mg}$ and $\mathrm{Fe}$ concentrations in olivine samples. Laser $1060 \mathrm{~nm}, 100 \mathrm{~mJ}$ per pulse, $20 \mathrm{~Hz}$, slit 50 micrometer; measurement time $5 \mathrm{~s}$.

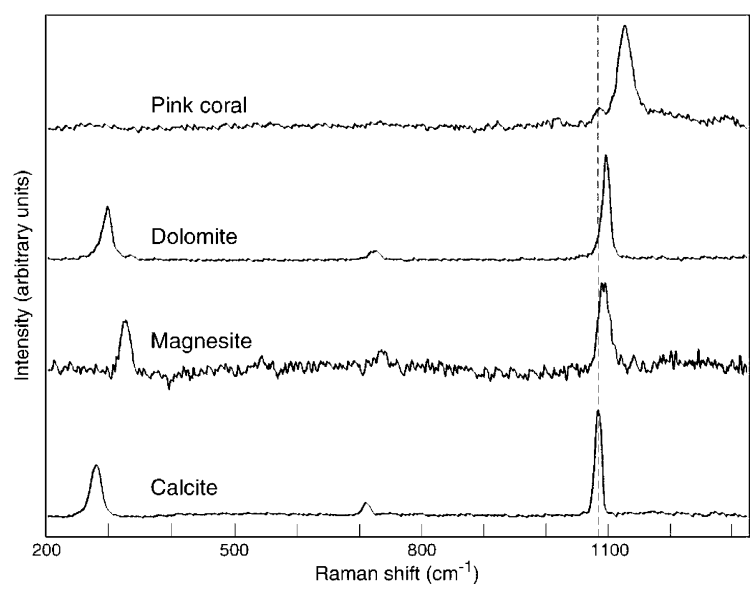

Fig. 18. Portions of the Raman spectra of biogenic (pink coral) and abiogenic carbonates recorded with the combined LIBS/ Raman spectroscopic system at a stand off distance of $10-\mathrm{m}$. Raman bands near $1085 \mathrm{~cm}^{-1}$ are characteristic of the $\mathrm{CO}_{3}^{2-}$ ions.

is very strong in the Raman spectra of calcite, magnesite, and dolomite and is very weak in the spectrum of pink coral. The presence of the band at $\sim 1085 \mathrm{~cm}^{-1}$ in spectra of these samples indicates that these minerals contain $\mathrm{CO}_{3}^{2-}$ ions [41]. The strong Raman band at $1130 \mathrm{~cm}^{-1}$ in the spectrum of pink coral is characteristic of resonance Raman spectra of the carotene pigment [27] and implies biogenic origin of this sample. The low frequency lattice modes of calcite, magnesite, and dolomite, respectively, appear at 281, 329, and 299 $\mathrm{cm}^{-1}$ (Fig. 18) and can be used to identify the types of carbonate minerals. The lattice modes are very weak and broad in the spectrum of pink coral because of disorder and the nano-crystalline nature of the biogenic carbonate [27]. The quantitative information about cations from the LIBS data, when combined with the unique Raman signature of the anion groups, will allow us to remotely identify and characterize the composition and mineralogy of crystals and rocks on planetary surfaces. The remote LIBS and Raman data on selected minerals clearly demonstrate that development of a combined LIBS and Raman instrument will be very useful for planetary applications.

These results indicate that the stand-off LIBS/ pulsed Raman system can be used to analyze both a-biogenic and biogenic minerals and various 
types of ices on planetary surfaces to a distance of at least $10 \mathrm{~m}$. Efforts are underway for combining the stand-off pulsed Raman and LIBS techniques into a compact single instrument for stand-off in situ mineralogical and elemental analysis of planetary surfaces.

\section{Conclusions}

Technological advances have made it feasible for us to design and evaluate prototypes of compact and efficient telescopic Raman systems, as well as a prototype of the combined LIBS/ Raman spectroscopic system for stand-off analysis of minerals and rocks on planetary surfaces. The stand-off Raman system is capable of measuring spectra to a distance of $66 \mathrm{~m}$ with medium power $\mathrm{CW}$ and pulsed laser sources. The stand-off LIBS measurements are made on selected minerals to a distance of $10 \mathrm{~m}$. It has been demonstrated that with our field-portable pulsed Raman spectroscopic system equipped with an efficient spectrometer, weak Raman spectra of silicate glasses and of atmospheric gases can be measured at a distance of $10 \mathrm{~m}$ from the telescope. We have presented high quality Raman spectra of a number of silicate and carbonate minerals measured from a stand-off distance in the range 5.1-66 $\mathrm{m}$ with pulsed and CW telescopic Raman system. The quality of the data is sufficient to unambiguously determine the anionic groups present within the minerals and in most cases further constrain the mineral composition based on the low frequency lattice modes. The stand-off LIBS and Raman data on selected minerals have clearly demonstrated that development of a combined telescopic LIBS and Raman instrument is feasible and that such an instrument will be very useful for planetary applications.

The power consumption, size and weight of stand-off Raman systems can be lowered and made consistent with the power and resources of current Mars landers by incorporating diodepumped frequency doubled solid state lasers. Stand-off Raman spectroscopy and combined LIBS/Raman spectroscopy are feasible remote sensing techniques for Mars with optimization of mass and volume of various components. Our field portable pulsed Raman spectroscopic system is a suitable candidate for mineral analysis on planetary surfaces and will find many other applications including analysis of various types of ores, industrial monitoring of silicate melts and glasses, gases, and organic materials including explosives, large archeological objects and ancient paintings.

\section{Acknowledgements}

NASA largely supported this work under grant NAG5-7139. Partial support was also provided by ONR under grant N00014-96-1-0317 and the University of Hawaii Foundation. We are grateful to Professor Michael Angel of the University of South Carolina for providing his HoloSpec 1.8 spectrometer on loan for the initial phase of this work. Assistance of Dr Anupam Misra for making Raman measurements with the field portable pulsed Raman system is very much appreciated. We thank David Hampton for machining various parts of laser mount. We acknowledge with great appreciation the ongoing discussions with $\mathrm{Dr}$ Roger Wiens and Dr David Cremers of the Los Alamos National Laboratory regarding development of a combined LIBS/Raman spectroscopic system for planetary exploration. One of us (S.K. Sharma) would like to thank Professor Jan Jejlicka of Charles University, Prague, Czech Republic for his kind invitation to present this work at the GEORAMAN 2002-the Fifth International Conference on Raman spectroscopy Applied to Earth Sciences. This is SOEST contribution no. 6127 and HIGP contribution no. 1270.

\section{References}

[1] A. Wang, B.L. Jolliff, L.A. Haskin, J. Geophys. Res. 104 (1999) 8509.

[2] T.F. Cooney, E.R.D. Scott, A.N. Krot, S.K. Sharma, A. Yamaguchi, Am. Mineral. 84 (1999) 1569.

[3] T.J. Fagan, E.R.D. Scott, K. Keil, T.F. Cooney, S.K. Sharma, Meteorit. Planet. Sci. 35 (2000) 319.

[4] E.J. Israel, R.E. Arvidson, A. Wang, J.D. Pasteris, B.L. Jolliff, J. Geophys. Res. 102 (1997) 28, 705.

[5] B.L. Jolliff, A. Wang, K. Kuebler, L.A. Haskin, G. Klingelhöfer, Lunar Planet. Sci. 30 (1999) 1529. 
[6] L.A. Haskin, A. Wang, K.M. Rockow, B.L. Jolliff, R.L. Korotev, K.M. Viskupic, J. Geophys. Res. 102 (1997) 19293.

[7] A. Wang, L.A. Haskin, E. Cortez, Appl. Spectrosc. 52 (1998) 477.

[8] P.G. Lucey, T.F. Cooney, S.K. Sharma, Lunar Planet. Sci. 29 (1998) 1354.

[9] K.A. Horton, N. Domergue-Schmidt, S.K. Sharma, P. Deb, P.G. Lucey, Lunar Planet. Sci. 31 (2000) 1514.

[10] S.K. Sharma, S.M. Angel, M. Ghosh, H.W. Hubble, P.G. Lucey, Appl. Spectrosc. 56 (2002) 699.

[11] J.A. Bolger, Appl. Spectrosc. 54 (2000) 181.

[12] D.A. Cramers, M.J. Ferris, Appl. Spectrosc. 54 (2000) 331.

[13] R.J. Hemely, H.K. Mao, Science 237 (1987) 605.

[14] P.F. McMillan, A.M. Hofmeister, Infrared and Raman spectroscopy, in: F.C. Hawthorne (Ed.), Spectroscopic Methods in Mineralogy and Geology, Review in Mineralogy, vol. 18, Mineralogical Society of America, Washington, DC, 1988, p. 99.

[15] S.K. Sharma, Applications of Raman spectroscopy in earth and planetary sciences, in: K. Gopalan, V.K. Gaur, B.L.K. Somayajulu, J.D. Macdougall (Eds.), From Mantle to Meteorites: A Garland of Perspectives, Festschrift for Devendral Lal, Indian Academy of Science, Banglore, India, 1990, p. 263.

[16] P. Gillet, G. Fiquet, I. Daniel, B. Reynard, Geophys. Res. Lett. 20 (1993) 1931.

[17] D. Schiferl, S.K. Sharma, T.F. Cooney, K. Mohanan, Rev. Sci. Instrum. 64 (1993) 2831.

[18] S.Y. Wang, S.K. Sharma, T.F. Cooney, Am. Mineral. 78 (1993) 469.

[19] H. Boyer, D. Smith, C. Chopin, B. Lasnier, Phys. Chem. Mineral 12 (1985) 45.

[20] J. Jehlicka, C. Beny, J.N. Rouzaud, J. Raman Spectrosc. 28 (1997) 717.

[21] J.D. Pasteris, The laser Raman microprobe as a tool for the economic geologist, in: M.A. McKibben, W.C. Shanks, W.I. Ridley (Eds.), Applications of Micro-analytical Techniques to Understanding Mineralizing Processes, Society of Economic Geologists, Littleton, Colorado, 1998, p. 233.

[22] J. Dubessy, D. Audeoud, R. Wilkins, C. Kosztolanyi, Chem. Geol. 37 (1982) 137.

[23] A. Derbyshire, R. Whithnall, J. Raman Spectrosc. 30 (1999) 185.

[24] D.C. Smith, F. Gendron, J. Raman Spectrosc. 28 (1997) 731.

[25] H.G.M. Edwards, D.W. Farwell, F.R. Perez, J.M. Garcia, Analyst 124 (1999) 1323.
[26] W.D. Bischoff, S.K. Sharma, F.T. Mackenzie, Am. Mineral. 70 (1985) 581.

[27] J.P. Urmos, S.K. Sharma, F.T. Mackenzie, Am. Mineral. 76 (1991) 641.

[28] D.D. Wynn-Williams, H.G.M. Edwards, Icarus 144 (2000) 486.

[29] A. Wang, B.L. Jolliff, L.A. Haskin, J. Geophys. Res. 100 (1995) 189.

[30] A. Wang, B.L. Jolliff, L.A. Haskin, J. Geophys. Res., 104 (1999) $27,067$.

[31] T. Hirschfeld, Appl. Optics 13 (1974) 1435.

[32] S.M. Angel, T.J. Kulp, T.M. Vess, Appl. Spectrosc. 46 (1992) 1085.

[33] R.M. Measures, Laser Remote Sensing, Fundamentals and Applications, Wiley, New York, 1984.

[34] D.N. Whiteman, K.D. Evans, B. Demoz, D.O.'C. Starr, D. Tobin, W. Feltz, G.J. Jedlovec, S.I. Gutman, G.K. Schwemmer, M. Cadirola, S.H. Melfi, F.J. Schmidlin, J. Geophys. Res. 106 (2000) 5211.

[35] M. Wu, M. Ray, K.H. Fung, M.W. Ruckman, D. Harder, A.J. Sedlacek, III, Appl. Spectrosc. 54 (2000) 800.

[36] K.A. Horton, S.K. Sharma, N. Domergue-Schmidt, P.G. Lucey, Lunar Planet. Sci. 32 (2001) 1662.

[37] S.K. Sharma, S.M. Angel, M. Ghosh, H.W. Hubble, P.G. Lucey, Lunar Planet. Sci. 32 (2001) 2066.

[38] S.K. Sharma, Z. Wang, S. van der Laan, J. Raman Spectrosc. 27 (1996) 739.

[39] D.W. Matson, S.K. Sharma, J.A. Philpotts, Am. Mineral. 71 (1986) 694.

[40] S.K. Sharma, B. Simons, H.S. Yoder, Jr, Am. Mineral. 68 (1983) 1113.

[41] W.B. White, The carbonate minerals, in: V.C. Farmer (Ed.), Infrared Spectra of Minerals (Chapter 12), Mineralogical Society, London, 1974, p. 227 (Chapter 12).

[42] L.M. Sverdlov, M.A. Kovner, E.P. Krainov, Vibrational Spectra of Polyatomic Molecules, Wiley, New York, 1974.

[43] S.K. Sharma, Vibration. Spectra Struct. 17B (1989) 513568.

[44] H.H. Eysel, J.E. Bertie, J. Raman Spectrosc. 19 (1988) 59.

[45] K.G. Ray, R.L. McCreery, Appl. Spectrosc. 51 (1997) 108.

[46] P.J. Hendra, Raman instrumentation and sampling, in: R.J.G. Miller, B.C. Stace (Eds.), Laboratory Methods in Infrared Spectroscopy (Chapter 15), Heyden \& Sons, London, 1972, p. 230 (Chapter 15).

[47] C.H. Chio, S.K. Sharma, P.G. Lucey, D.W. Muenow, Lunar Planet. Sci. 32 (2001) 1471.

[48] A. Wang, Lunar Planet. Sci. 30 (1999) 1644.

[49] H.W. Hubble, M. Ghosh, S.K. Sharma, K.A. Horton, P.G. Lucey, S.M. Angel, R.C. Wiens, Lunar Planet. Sci. 33 (2002) 1935. 